\title{
Neonatal Hemoglobin Levels in Preterm Infants Are Associated with Early Neurological Functioning
}

\author{
Willemien S. Kalteren ${ }^{a}$ Mirthe J. Mebius ${ }^{a}$ Elise A. Verhagen ${ }^{b}$ Jozien C. Tanis ${ }^{a}$ \\ Elisabeth M.W. Kooi ${ }^{\text {a }}$ Arend F. Bos ${ }^{\text {a }}$ \\ aDivision of Neonatology, Department of Pediatrics, Beatrix Children's Hospital, University of Groningen, \\ University Medical Center Groningen, Groningen, The Netherlands; ${ }^{b}$ Division of Neonatology, Department of \\ Pediatrics, Amsterdam University Medical Center, location VU Medical Center, Amsterdam, The Netherlands
}

\section{Keywords}

Neonatal anemia · Preterm infants · General movements ·

Neurological functioning

\begin{abstract}
Background: Neonatal anemia may compromise oxygen transport to the brain. The effects of anemia and cerebral oxygenation on neurological functioning in the early neonatal period are largely unknown. Objective: This study aimed to determine the association between initial hemoglobin levels $(\mathrm{Hb})$ and early neurological functioning in preterm infants by assessing their general movements (GMs). Methods: A retrospective analysis of prospectively collected data on preterm infants born before 32 weeks of gestation was conducted. We excluded infants with intraventricular hemorrhage > grade II. On day 8, we assessed infants' GMs, both generally as normal/abnormal and in detail using the general movement optimality score (GMOS). We measured cerebral tissue oxygen saturation $\left(\mathrm{r}_{\mathrm{C}} \mathrm{SO}_{2}\right)$ on day 1 using nearinfrared spectroscopy. Results: We included 65 infants (median gestational age 29.9 weeks [IQR 28.2-31.0]; median birth weight $1,180 \mathrm{~g}$ [IQR 930-1,400]). Median Hb on day 1 was $10.3 \mathrm{mmol} / \mathrm{L}$ (range 4.2-13.7). Lower $\mathrm{Hb}$ on day 1 was
\end{abstract}

karger@karger.com www.karger.com/neo

Karger $\stackrel{\text { ' }}{5}$

bOPEN ACCESS
(C) 2021 The Author(s)

Published by S. Karger AG, Basel

This is an Open Access article licensed under the Creative Commons Attribution-NonCommercial-4.0 International License (CC BY-NC) (http://www.karger.com/Services/OpenAccessLicense), applicable to the online version of the article only. Usage and distribution for commercial purposes requires written permission. associated with a higher risk of abnormal GMs (OR $=2.3,95 \%$ $\mathrm{Cl}$ : 1.3-4.1) and poorer GMOSs ( $B=0.9,95 \% \mathrm{Cl}: 0.2-1.7)$. Hemoglobin strongly correlated with $\mathrm{r}_{\mathrm{c}} \mathrm{SO}_{2}$ ( $\mathrm{rho}=0.62, p<$ 0.01 ). Infants with lower $\mathrm{r}_{\mathrm{c}} \mathrm{SO}_{2}$ values tended to have a higher risk of abnormal GMs $(p=0.06)$. After adjusting for confounders, $\mathrm{Hb}$ on day 1 explained $44 \%$ of the variance of normal/abnormal GMs and $\mathrm{r}_{\mathrm{c}} \mathrm{SO}_{2}$ explained $17 \%$. Regarding the explained variance of the GMOS, this was $25 \%$ and $16 \%$, respectively. Conclusions: In preterm infants, low Hb on day 1 is associated with impaired neurological functioning on day 8 , which is partly explained by low cerebral oxygenation.

(c) 2021 The Author(s)

Published by S. Karger AG, Basel

\section{Introduction}

Neonatal anemia is common in preterm infants. Anemia may induce tissue hypoxia, possibly resulting in cell injury. Red blood cell (RBC) transfusions aim to rapidly improve oxygen transport to vital organs. Up to $60 \%$ of preterm infants born before 32 weeks of gestational age (GA) receive $\mathrm{RBC}$ transfusions for anemia, mainly as a result of iatrogenic phlebotomy loss and when ventilatory support is required to improve oxygen delivery [1]. Ane- 
mia and RBC transfusions are strongly related during the first days after birth [2] and are associated with mortality and short-term morbidity, such as hemodynamic significant patent ductus arteriosus (PDA) and intraventricular hemorrhage (IVH) $[2,3]$.

Severe neonatal anemia leads to decreased oxygen transport and decreased oxygenation in the brain [4]. This is associated with adverse effects on maturation of the central nervous system and subsequent neurodevelopment [5]. Conversely, RBC transfusions increase cerebral tissue oxygenation, which may benefit infants' neurological condition [6]. Transfusions could, however, also induce oxidative stress and subsequent neuronal injury. Contradictory results were published on long-term outcomes in infants treated according to either liberal or restrictive RBC transfusion guidelines during neonatal intensive care unit (NICU) stay [7, 8]. Early neurological assessment may bring to light the underlying pathophysiological mechanisms.

The effects of anemia and cerebral oxygenation on neurological functioning in the early neonatal period are largely unknown. A widely applied method to monitor cerebral tissue oxygen saturation $\left(\mathrm{r}_{\mathrm{c}} \mathrm{SO}_{2}\right)$ in neonates is near-infrared spectroscopy (NIRS). Cerebral oxygenation measures can also serve as a prognostic tool for predicting outcomes in preterm infants $[6,9]$. A reliable and valid tool to determine neurological functioning in young infants is Prechtl's method of general movement assessment (GMA) [10,11]. The quality of general movements (GMs), combined with detailed aspects of these movements as reflected in the general movement optimality score (GMOS), is of significant diagnostic value in preterm infants $[12,13]$, with fair to good prognostic value after the first postnatal week [14].

The aim of our study was to determine the association between initial hemoglobin levels $(\mathrm{Hb})$ and GMA on day 8 after birth in preterm infants born before 32 weeks of gestation. We hypothesize that low $\mathrm{Hb}$ and its concomitant low cerebral oxygenation is independently associated with poorer neurological functioning.

\section{Methods}

Study Design and Participants

We performed a retrospective analysis on prospectively collected data on inborn and outborn preterm infants admitted to the NICU of the University Medical Center Groningen (UMCG) between May 2006 and April 2018. They were either part of a previously published prospective observational study $[6,15]$ or a recent unpublished observational pilot study on the feasibility of adding early GMA to standard NICU in all preterm born infants $\leq 30$ weeks of gestation. Inclusion criteria of the previous 2 trials were GA $<32$ weeks in one of them [6] and fetal growth restriction defined as fetal abdominal circumference or estimated fetal weight $<10$ th percentile or declining fetal growth $\geq 30$ percentiles in the other [15]. Both studies were approved by the UMCG Medical Ethics Review Board.

Infants were eligible for the current study if they met the following criteria: GA $\leq 32$ weeks and a video recording of GMs on day 8 after birth. We excluded infants with chromosomal abnormalities or if they were diagnosed with an IVH $>$ grade II, according to Papile's classification, to prevent inclusion of cases where abnormal GMs were a result of severe IVH. Transfusion thresholds were according to the Dutch anemia transfusion protocol (online suppl. Table 1; see www.karger.com/doi/10.1159/000518655 for all online suppl. material).

\section{Video Recordings and Movement Optimality Scores}

Our primary outcome was the quality of GMs, including detailed scoring, on day 8 . This was obtained from a 45-min video recording, in accordance with Einspieler and Prechtl [11]. Because from the end of the first week onward GMA is reliable with even a moderate prognostic value [14], we assessed the neurological condition on day 8 , being close to the risk factor of interest, that is, $\mathrm{Hb}$ on day 1 . The infant was laid in the supine position, wearing only a diaper. Recordings during crying, fussing, hiccupping, or sucking on a pacifier were excluded from analyses [11]. All recordings were evaluated offline by 2 researchers (W.S.K. and A.F.B.). We first categorized the GMs into normal, poor repertoire, crampedsynchronized, or chaotic GMs [11]. Subsequently, we scored their detailed characteristics using the GMOS. The first part of the GMOS refers to the general GM categories. The second part focuses on detailed scoring of the neck and trunk and upper and lower extremities, separately. The GMOS results from adding the scores of the 3 categories plus the score for general quality. A score of 42 indicates the best possible performance and 5 the poorest [12]. In case of absent or only very brief GMs $(<3 \mathrm{~s})$, the infant was classed as hypokinetic, and a GMOS was not performed.

\section{Clinical Variables}

Hemoglobin on day 1 was retrieved from the infants' medical records. From these records, we also collected other clinical data including GA, birth weight (BW), $\mathrm{Hb}$ on day 8 , the $\mathrm{RBC}$ transfusions administered, Apgar score, illness severity assessed according to the Score for Neonatal Acute Physiology-Perinatal Extension II (SNAPPE-II) [16], presence of a PDA, and mechanical ventilation.

We measured $\mathrm{r}_{c} \mathrm{SO}_{2}$ using NIRS, a noninvasive procedure, and used the INVOS $5100 \mathrm{c}$ oximeter in combination with neonatal sensors (Medtronic, Dublin, Ireland). The sensor was placed on either the left or right side of the infants' forehead. We calculated mean $\mathrm{r}_{\mathrm{c}} \mathrm{SO}_{2}$ of a 2 -h recording on day 1 , in which the correct sensor position was documented. We used the mean $\mathrm{r}_{\mathrm{c}} \mathrm{SO}_{2}$ obtained for each individual infant for analyses.

\section{Statistical Analyses}

We used SPSS version 23.0 (IBM Corp., Armonk, NY, USA) for statistical analyses. Patient characteristics were described as median interquartile range (IQR) or number $(n)$ percentage. Using Pearson's correlation test, we calculated the correlation coefficient between infants' $\mathrm{Hb}$ on day 1 and $\mathrm{r}_{\mathrm{c}} \mathrm{SO}_{2}$. Next, we calculated odds ratios and $95 \%$ confidence intervals for abnormal GMs. We also 


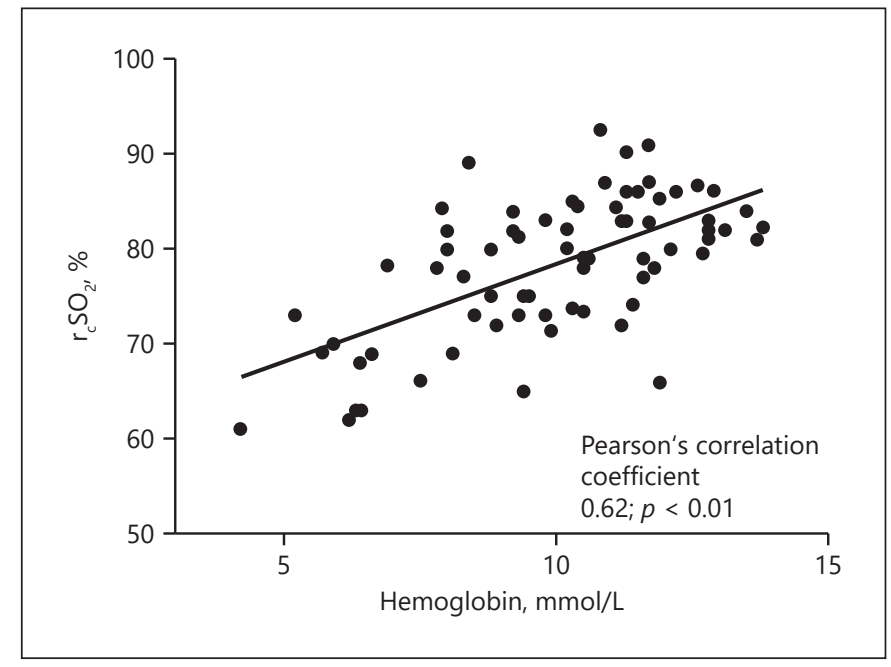

Fig. 1. Relation between hemoglobin level and cerebral tissue oxygen saturation on day $1 . \mathrm{r}_{\mathrm{c}} \mathrm{SO}_{2}$, cerebral tissue oxygen saturation.

performed linear regression analyses to test whether Hb on day 1 , $\mathrm{Hb}$ during video recording on day 8 , and cerebral oxygenation were predictive of GMOS. The potential confounders we considered were infants' year of birth, GA, Apgar scores, illness severity, and whether they were born small-for-gestational age (SGA). These factors, which were univariately associated with either abnormal GMs or GMOS at $p<0.20$, were included in multiple regression models, taking the potential influence of multicollinearity into account. Statistical significance was defined as $p<0.05$.

Because our cohort had a fixed number of infants, we were hesitant to perform a power analysis. Nevertheless, we calculated how many infants we required for this study to make a meaningful conclusion. Regarding the association between GMOS and $\mathrm{Hb}$ on day 1 , we considered a correlation coefficient of 0.4 as relevant. With a power of 0.8 and alpha 0.05 , we needed to include 43 infants or 61 infants if we would include 2 covariates in the analyses.

\section{Results}

\section{Participants and Video Recordings}

We included 65 infants with a median GA of 29.9 weeks (IQR 28.2-31.1) and a median BW of 1,180 g (IQR 930-1,403). Of them, 46 were born between 2006 and 2007, 16 between 2012 and 2014, and 3 in 2018. Median $\mathrm{Hb}$ on day 1 was $10.3 \mathrm{mmol} / \mathrm{L}$ (range 4.2-13.7). Median $\mathrm{r}_{\mathrm{c}} \mathrm{SO}_{2}$ on day 1 was $80 \%$ (IQR 73-84). Twenty infants (31\%) received an RBC transfusion before day 8. Hemoglobin on day 8 ranged from 6.1 to $12.5 \mathrm{mmol} / \mathrm{L}$. Baseline characteristics are depicted in Table 1.

In Table 2, we present the classification of the quality of the GMs and the GMOSs. Seven infants were classed as hypokinetic on account of sepsis. The GMOS was as-
Table 1. Patient characteristics

\begin{tabular}{|c|c|}
\hline & $\begin{array}{l}\text { Median (range) or } \\
n(\%)\end{array}$ \\
\hline Gestational age, weeks & $29.9(26.0-31.9)$ \\
\hline Birth weight, g & $1,180(560-2,250)$ \\
\hline SGA & $36(55)$ \\
\hline LGA & $6(9)$ \\
\hline Sex, male & $26(40)$ \\
\hline Apgar score at $5 \mathrm{~min}$ & $8(3-10)$ \\
\hline SNAPPE-II & $14(5-39)$ \\
\hline \multicolumn{2}{|l|}{ Hemoglobin, $\mathrm{mmol} / \mathrm{L}$} \\
\hline On day 1 & $10.3(4.2-13.7)$ \\
\hline On day 8 & $8.4(6.1-12.5)$ \\
\hline $\mathrm{r}_{\mathrm{c}} \mathrm{SO}_{2}$ on day $1, \%$ & $80(61-91)$ \\
\hline Infants with $\mathrm{r}_{\mathrm{c}} \mathrm{SO}_{2}$ below $72 \%$ on day 1 & $12(18)$ \\
\hline $\mathrm{RBC}$ transfusion received & $34(52)$ \\
\hline Before day 8 & $20(31)$ \\
\hline Mechanical ventilation $^{\text {a }}$ & $42(65)$ \\
\hline On day 8 & $8(12)$ \\
\hline Treatment with inotropes ${ }^{\mathrm{b}}$ on day 1 & $8(12)$ \\
\hline $\mathrm{PDA}^{\mathrm{c}}$ & $22(34)$ \\
\hline IVH grades I-II & $10(15)$ \\
\hline Survival during NICU stay & $59(91)$ \\
\hline
\end{tabular}

SGA, small-for-gestational age ( $<10$ th percentile); LGA, largefor-gestational age ( $>90$ th percentile); SNAPPE-II, score for neonatal acute physiology-perinatal extension $\mathrm{II} ; \mathrm{r}_{\mathrm{c}} \mathrm{SO}_{2}$, cerebral tissue oxygen saturation; RBC, red blood cell; PDA, patent ductus arteriosus; IVH, intraventricular hemorrhage. ${ }^{a}$ Mechanical ventilation indicates synchronized intermittent positive pressure ventilation, synchronized intermittent mechanical ventilation, or highfrequency oscillation. $b$ Treatment with dopamine and/or dobutamine. ${ }^{c}$ PDA indicates a hemodynamically significant leftto-right shunt that required treatment according to the team of neonatologists and cardiologists, that is, a symptomatic PDA.

Table 2. The quality of the general movements and the optimality score

Median (range) or $n(\%)$

Quality of GMs

Normal GMs $11(17)$

Poor repertoire $\quad 47(72)$

Chaotic $0(0)$

Cramped-synchronized $\quad 0(0)$

Motor optimality score

GMOS

$27(18-42)$

Not assessable

Hypokinetic

$7(11)$

GMs, general movements; GMOS, general movement optimality score. 
Table 3. Odds ratios for risk factors in relation to abnormal GMs on day 8 using univariate and multiple regression analyses

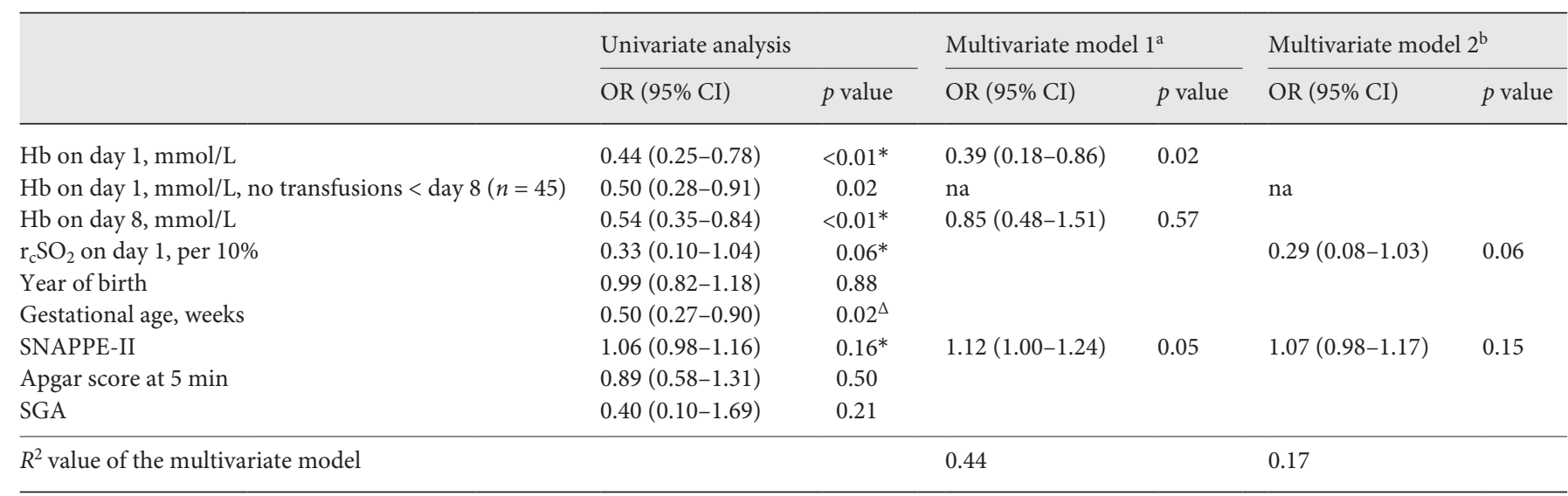

GMs, general movements; OR, odds ratio; CI, confidence interval; $\mathrm{Hb}$, hemoglobin; na, not applicable; $\mathrm{r}_{\mathrm{c}} \mathrm{SO}_{2}$, cerebral tissue oxygen saturation; SNAPPEII, score for neonatal acute physiology-perinatal extension II; SGA, small-for-gestational age ( $<10$ th percentile). ${ }^{*} p<0.2$, included in the multivariate model. ${ }^{\Delta}$ Not included in multivariate models because of multicollinearity. ${ }^{a}$ Included in this model were $\mathrm{Hb}$ on day 1 , Hb on day 8 , and SNAPPE-II. ${ }^{\mathrm{b}}$ Included in this model were $\mathrm{r}_{\mathrm{c}} \mathrm{SO}_{2}$ and SNAPPE-II.

Table 4. Relation between risk factors and GMOS on day 8 using univariate and multiple regression analyses

\begin{tabular}{|c|c|c|c|c|c|c|}
\hline & \multicolumn{2}{|l|}{ Univariate analysis } & \multicolumn{2}{|l|}{ Multivariate model $1^{\mathrm{a}}$} & \multicolumn{2}{|l|}{ Multivariate model $2^{\mathrm{b}}$} \\
\hline $\mathrm{Hb}$ on day $1, \mathrm{mmol} / \mathrm{L}$, no transfusions $<$ day $8(n=45)$ & $0.29(-1.02$ to 1.61$)$ & 0.66 & na & & na & \\
\hline $\mathrm{Hb}$ on day $8, \mathrm{mmol} / \mathrm{L}$ & $0.88(-0.13$ to 1.89$)$ & $0.09 *$ & $0.29(-0.72$ to 1.29$)$ & 0.57 & & \\
\hline $\mathrm{r}_{\mathrm{c}} \mathrm{SO}_{2}$ on day 1 , per $10 \%$ & $1.49(-0.88$ to 3.86$)$ & $0.19^{*}$ & & & $1.14(-1.11$ to 3.38$)$ & 0.31 \\
\hline SNAPPE-II & $-0.27(-0.44$ to -0.09$)$ & $<0.01^{*}$ & $-0.27(-0.44$ to -0.10$)$ & $<0.01$ & $-0.26(-0.43$ to -0.08$)$ & 0.01 \\
\hline Apgar score at $5 \mathrm{~min}$ & $0.21(-0.88$ to 1.30$)$ & 0.70 & & & & \\
\hline SGA & $0.37(-3.00$ to 3.73$)$ & 0.83 & & & & \\
\hline$R^{2}$ value of the multivariate model & & & 0.25 & & 0.16 & \\
\hline
\end{tabular}

GMOS, general movement optimality score; $\mathrm{B}$, unstandardized coefficient; $\mathrm{CI}$, confidence interval; $\mathrm{Hb}$, hemoglobin; na, not applicable; $\mathrm{r}_{\mathrm{c}} \mathrm{SO}_{2}$, cerebral tissue oxygen saturation; SNAPPE-II, score for neonatal acute physiology-perinatal extension II; SGA, small-for-gestational age $\left(<10\right.$ th percentile). ${ }^{*} p<0.2$, included in the multivariate model. ${ }^{\Delta}$ Not included in multivariate models because of multicollinearity. ${ }^{\mathrm{a}}$ Included in this model were $\mathrm{Hb}$ on day 1 , Hb on day 8 , and SNAPPE-II. ${ }^{b}$ Included in this model were $\mathrm{r}_{\mathrm{c}} \mathrm{SO}_{2}$ and SNAPPE-II.

sessed in 58 (89\%) infants. Of these, 11 infants (19\%) had normal GMs and 47 (81\%) had poor repertoire GMs. The median GMOS was 27 (IQR 23-33).

\section{Relation between $\mathrm{Hb}$, Cerebral Oxygenation, and Quality of GMs}

Low $\mathrm{Hb}$ on both day 1 and day 8 was associated with a higher risk of abnormal GMs on day 8 (Table 3). Hemoglobin on day 1 correlated strongly with mean $\mathrm{r}_{\mathrm{c}} \mathrm{SO}_{2}$ on day 1 (Fig. 1). Low $\mathrm{r}_{\mathrm{c}} \mathrm{SO}_{2}$ tended to be associated with a higher risk of abnormal GMs (Table 3). Higher GA was associated with lower risk of abnormal GMs. Neither year of birth, Apgar score, SNAPPE-II, nor SGA was significantly related to abnormal GMs.

Because $\mathrm{Hb}$ correlated strongly with $\mathrm{r}_{\mathrm{c}} \mathrm{SO}_{2}$, we entered $\mathrm{Hb}$ and $\mathrm{r}_{\mathrm{c}} \mathrm{SO}_{2}$ into separate regression models to avoid multicollinearity. After adjusting for illness severity, only $\mathrm{Hb}$ on day 1 remained significantly associated with abnormal GMs on day 8, with model 1 explaining $44 \%$ of the variance (Table 3 ). The association remained signifi- 
cant when only the 45 infants were analyzed who did not receive an $\mathrm{RBC}$ transfusion before day 8 . With regard to its association with abnormal $\mathrm{GMs}, \mathrm{r}_{\mathrm{c}} \mathrm{SO}_{2}$ just failed to reach significance $(p=0.06)$, with model 2 explaining $17 \%$ of the variance.

\section{Relation between $\mathrm{Hb}$, Cerebral Oxygenation, and GMOS}

Low $\mathrm{Hb}$ on day 1 was associated with lower GMOSs on day 8 (Table 4). The association disappeared when only infants who did not receive a transfusion within the first week were analyzed. $\mathrm{r}_{\mathrm{c}} \mathrm{SO}_{2}$ was not significantly associated with GMOS $(p=0.19)$. Lower GA and higher SNAPPE-II scores were related to lower GMOSs on day 8, while year of birth, Apgar scores, and SGA were not.

In Table 4, we present 2 separate multivariate models to test whether $\mathrm{Hb}$ and $\mathrm{r}_{\mathrm{c}} \mathrm{SO}_{2}$ contributed to the GMOSs. After checking the univariate betas, SNAPPE-II scores, and not GA, were entered in the multivariate models. Both $\mathrm{Hb}$ on day 1 and illness severity remained associated with GMOS on day 8 , with model 1 explaining $25 \%$ of the variance, whereas $\mathrm{r}_{\mathrm{c}} \mathrm{SO}_{2}$ did not, with model 2 explaining $16 \%$ of the variance.

\section{Discussion}

We demonstrated that in preterm infants, low $\mathrm{Hb}$ on the first day after birth was associated with impaired neurological functioning on day 8 as measured in terms of the quality of GMs, including the detailed characteristics of these movements. On day 1, cerebral oxygenation, which is strongly related to $\mathrm{Hb}$, tended to be associated with early neurological functioning. Cerebral injury associated with low $\mathrm{Hb}$ on day 1 might be mediated through lower $\mathrm{r}_{\mathrm{c}} \mathrm{SO}_{2}$, irrespective of illness severity.

As we hypothesized, low $\mathrm{Hb}$ after birth negatively affected the neurological condition of preterm infants on day 8. Early GMs were assessed only 1 week later, which supported the notion of causality between $\mathrm{Hb}$ on day 1 and poor neurological functioning on day 8 . The infants had no history of other diseases that might also have affected neurological functioning: $\mathrm{Hb}$ remained strongly related to neurological functioning after adjusting for illness severity. In part, the association between $\mathrm{Hb}$ and GMs may be mediated by low $\mathrm{r}_{\mathrm{c}} \mathrm{SO}_{2}$ on day 1 , seeing that $\mathrm{r}_{\mathrm{c}} \mathrm{SO}_{2}$ was strongly correlated to $\mathrm{Hb}$. Low $\mathrm{Hb}$, however, contributed to both abnormal GMs and lower GMOSs more strongly than $\mathrm{r}_{\mathrm{c}} \mathrm{SO}_{2}$. This might be explained by the fact that not only cerebral hypoxia but also cerebral

Early Hb Is Associated with Neurological

Functioning in Preterm Infants hyperoxia is associated with poorer outcomes [6], reducing the linear, statistically significant relationship between $\mathrm{r}_{\mathrm{c}} \mathrm{SO}_{2}$ and GMA. Hyperoxia and oxidative stress in particular are associated with white matter and neuronal injury $[17,18]$. Our results suggest that anemic hypoxia on day 1 may be harmful for the preterm brain. In line with our results, previous reports showed that increasing compensatory cerebral blood flow during anemia seems insufficient to normalize cerebral oxygenation [4].

A further explanation for the association between low $\mathrm{Hb}$ and poor neurological functioning may be that anemia is often associated with poorer hemodynamic stability and increased severity of cardiorespiratory illness and poorer short-term outcomes [19]. This is supported by the fact that early illness severity was also associated with GMA on day 8. Seeing that we excluded infants with severe IVH ( $\geq$ grade III), this could not have confounded our findings. All anemic infants received an RBC transfusion. Transfusions are also associated with poorer neurological outcomes in preterm infants [20]. Early RBC transfusions may, at least partly, account for any cerebral injury that may have developed within the first week after birth. Supposed pathophysiological mechanisms may be either an inflammatory response, ischemia-reperfusion injury, and/or oxidative stress [21].

$\mathrm{We}$ demonstrated that $\mathrm{Hb}$ on day 8 was not associated with neurological functioning on day 8 . This suggested that the most sensitive period for anemia-related cerebral injury is shortly after birth. A previous study also reported that low $\mathrm{Hb}$ directly after birth was associated with an increased risk of mortality and short-term morbidity [2]. Furthermore, maternal $\mathrm{Hb}$ within the optimal range during pregnancy is beneficial for gross motor development of infants [22] and supports this theory.

We performed GMA at the end of the first week. The quality of GMs and their detailed characteristics is a reliable indicator of neurological functioning in preterm infants from the first week after birth [14]. Although the prognostic value of abnormal GMs during the first week for long-term outcome may be limited, to date, several studies have reported that early abnormal GMs already identify preterm infants at risk of neurological sequelae [23] and cognitive deficits [24]. Further research should reveal whether this is also the case for the association of GMs with $\mathrm{Hb}$.

Our results suggest that cerebral development is hampered by hypoxia following the early anemic state of the preterm infants. It remains unclear, however, at which level of cerebral anemic hypoxia the benefits of $\mathrm{RBC}$ 
transfusion outweigh its disadvantages. The results of the SafeBoosC II trial did not confirm neurodevelopmental benefits of a reduced burden of cerebral hypoxia [25]. This study, however, was not powered to detect differences in neurodevelopmental impairments and did not restrict determining cerebral hypoxia to the first day, as we did. Previously it had been reported that cerebral hypoxia on day 1 is associated with impaired neurodevelopment $[6,9]$.

We recognize several limitations of our study. First, the retrospective design may have induced selection bias. The number of video recordings that was unsuitable for our purpose was rather high, considering that 7 infants were categorized as hypokinetic due to sepsis. This may have confounded our results, with sepsis being one of the mechanisms associated with white matter injury. Furthermore, the included sample consisted mainly of preterm born infants $>27$ weeks of GA. Second, we used data gathered during 3 different periods from 3 different observational studies. This may have resulted in varying clinical practices, although the year of birth was not associated with neurological functioning in our cohort. Furthermore, transfusion guidelines remained similar over the full time period. Third, because low $\mathrm{Hb}$ and transfusions are strongly interrelated, we could not entangle their separate effects on early neurological functioning. However, when performing the analyses in only infants who were not treated with a transfusion, the association between low $\mathrm{Hb}$ and poor neurological functioning remained. Fourth, infants born after fetal growth restriction were overrepresented in our cohort. Fetal growth restriction, however, did not significantly affect the results on neurological functioning.

\section{Conclusion}

This study aimed to investigate the effects of neonatal $\mathrm{Hb}$ on the early neurological condition of infants born before 32 weeks of gestation. In this group of preterm infants, low $\mathrm{Hb}$ on day 1 was indeed associated with poorer neurological functioning on day 8 . The correlation between low $\mathrm{Hb}$ and low cerebral oxygenation may reflect an underlying mechanism of cerebral anemic hypoxic injury or dysfunction. Further prospective studies should shed light on the question whether cerebral oxygenation dictates the need for RBC transfusions.

\section{Acknowledgments}

We thank Ms. A.J. Olthuis and Ms. D.H. Baptist for their help with recording of the general movements. We also thank Ms. T. van Wulfften Palthe, PhD, for correcting the English manuscript. This study was part of the research program of the Graduate School of Medical Sciences, Research Institute SHARE, University of Groningen.

\section{Statement of Ethics}

The study was approved by the Medical Ethics Review Board of the University Medical Center Groningen in accordance with the Helsinki Declaration (METc 2004/232, METc 2012/055, and METc 2013/263). All parents or guardians of the neonates provided their written informed consent regarding the use of clinical data and for making the video recordings.

\section{Conflict of Interest Statement}

All authors declare that they have nothing to disclose, financially or otherwise. There are no conflicts of interest.

\section{Funding Sources}

Ms. W.S. Kalteren received financial support from the Junior Scientific Master Class of the University of Groningen.

\section{Author Contributions}

Bos, Kalteren, and Kooi were involved in study concept and design; Kalteren and Mebius were involved in acquisition of data; Kalteren and Mebius were involved in analysis and interpretation of data; Tanis and Verhagen performed prospective studies; Kalteren drafted the manuscript; Bos, Kalteren, Kooi, Mebius, Tanis, and Verhagen critically revised the manuscript for important intellectual content; Bos and Kooi performed study supervision, both current and previous. All authors approved the final manuscript as submitted and agree to be accountable for all aspects of the work.

\section{Data Availability Statement}

All data generated or analyzed during this study are included in this article. Further enquiries can be directed to the corresponding author. 


\section{References}

1 Keir AK, Yang J, Harrison A, Pelausa E, Shah PS. Canadian neonatal network: temporal changes in blood product usage in preterm neonates born at less than 30 weeks' gestation in Canada. Transfusion. 2015;55(6):1340-6.

2 Banerjee J, Asamoah FK, Singhvi D, Kwan AW, Morris JK, Aladangady N. Haemoglobin level at birth is associated with short term outcomes and mortality in preterm infants. BMC Med. 2015;13:16.

3 Rocha G, Pereira S, Antunes-Sarmento J, Flôr-de-Lima F, Soares H, Guimarães H. Early anemia and neonatal morbidity in extremely low birth-weight preterm infants. J Matern Fetal Neonatal Med. 2019;17:1-7.

4 Van Hoften JC, Verhagen EA, Keating P, ter Horst HJ, Bos AF. Cerebral tissue oxygen saturation and extraction in preterm infants before and after blood transfusion. Arch Dis Child Fetal Neonatal Ed. 2010;95(5):F352-8.

5 Wang Y, Wu Y, Li T, Wang X, Zhu C. Iron metabolism and brain development in premature infants. Front Physiol. 2019;10:463.

6 Verhagen EA, Van Braeckel KN, van der Veere CN, Groen H, Dijk PH, Hulzebos CV, et al. Cerebral oxygenation is associated with neurodevelopmental outcome of preterm children at age 2 to 3 years. Dev Med Child Neurol. 2015;57(5):449-55.

7 Whyte RK, Kirpalani H, Asztalos EV, Andersen C, Blajchman M, Heddle N, et al. Neurodevelopmental outcome of extremely low birth weight infants randomly assigned to restrictive or liberal hemoglobin thresholds for blood transfusion. Pediatrics. 2009;123(1): 207-13.

8 McCoy TE, Conrad AL, Richman LC, Lindgren SD, Nopoulos PC, Bell EF. Neurocognitive profiles of preterm infants randomly assigned to lower or higher hematocrit thresholds for transfusion. Child Neuropsychol. 2011;17(4):347-67.
9 Alderliesten $\mathrm{T}$, van Bel F, van der Aa NE, Steendijk P, van Haastert IC, de Vries LS, et al. Low cerebral oxygenation in preterm infants is associated with adverse neurodevelopmental outcome. J Pediatr. 2019;207:109e2.

10 Prechtl HF, Einspieler C, Cioni G, Bos AF, Ferrari F, Sontheimer D. An early marker for neurological deficits after perinatal brain lesions. Lancet. 1997;349:1361-3.

11 Einspieler C, Prechtl HF. Prechtl's assessment of general movements: a diagnostic tool for the functional assessment of the young nervous system. Ment Retard Dev Disabil Res Rev. 2005;11:61-7.

12 Einspieler C, Marschik PB, Pansy J, Scheuchenegger A, Krieber M, Yang H, et al. The general movement optimality score: a detailed assessment of general movements during preterm and term age. Dev Med Child Neurol. 2016;58(4):361-8

13 Hempenius MA, Verhagen EA, Tanis JC, Einspieler C, Bos AF. Early neonatal morbidities and neurological functioning of preterm infants 2 weeks after birth. J Perinatol. 2018; 38(11):1518-25.

14 De Vries NK, Bos AF. The quality of general movements in the first ten days of life in preterm infants. Early Hum Dev. 2010;86(4): 225-9.

15 Tanis JC, Schmitz DM, Boelen MR, Casarella L, van den Berg PP, Bilardo CM, et al. Relationship between general movements in neonates who were growth restricted in utero and prenatal doppler flow patterns. Ultrasound Obstet Gynecol. 2016;48(6):772-8.

16 Richardson DK, Corcoran JD, Escobar GJ, Lee SK. SNAP-II and SNAPPE-II: simplified newborn illness severity and mortality risk scores. J Pediatr. 2001;138(1):92-100.
17 Maltepe E, Saugstad OD. Oxygen in health and disease: regulation of oxygen homeostatis-clinical implications. Pediatr Res. 2009;65: 261-8.

18 Reich B, Hoeber D, Bendix I, FelderhoffMueser U. Hyperoxia and the immature brain. Dev Neurosci. 2016;38:311-30.

19 Richardson DK, Gray JE, McCormick MC, Workman K, Goldmann DA. Score for neonatal acute physiology: a physiologic severity index for neonatal intensive care. Pediatrics. 1993;91:617-23.

20 Howarth C, Banerjee J, Aladangady N. Red blood cell transfusion in preterm infants: current evidence and controversies. Neonatology. 2018;114(1):7-16.

21 Crawford TM, Andersen CC, Hodyl NA Robertson SA, Stark MJ. The contribution of red blood cell transfusion to neonatal morbidity and mortality. J Paediatr Child Health. 2019;55(4):387-92.

22 Mireku MO, Davidson LL, Koura GK, Ouédraogo S, Boivin MJ, Xiong X, et al. Prenatal hemoglobin levels and early cognitive and motor functions of one-year-old children. Pediatrics. 2015;136(1):e76-83.

23 Olsen JE, Allinson LG, Doyle LW, Brown NC, Lee KJ, Eeles AL, et al. Preterm and termequivalent age general movements and 1-year neurodevelopmental outcomes for infants born before 30 weeks' gestation. Dev Med Child Neurol. 2018;60(1):47-53.

24 Bruggink JL, Van Braeckel KN, Bos AF. The early motor repertoire of children born preterm is associated with intelligence at school age. Pediatrics. 2010;125(6):e1356-63.

25 Plomgaard AM, Alderliesten T, van Bel F, Benders M, Claris O, Cordeiro M, et al. No neurodevelopmental benefit of cerebral oximetry in the first randomised trial (SafeBoosC II) in preterm infants during the first days of life. Acta Paediatr. 2019;108(2):275-81. 